\title{
An overview of extended-spectrum beta-lactamases in veterinary medicine and their public health consequences
}

\author{
Diego Borin Nóbrega, Marcelo Brocchi \\ Department of Genetics, Evolution, and Bioagents, University of Campinas, Campinas, Brazil
}

\begin{abstract}
Serious human and animal infections caused by bacteria are usually treated with beta-lactams. Extended-spectrum beta-lactamases (ESBLs) constitute the most clinically and economically important enzymes that are able to hydrolyze and inactivate beta-lactam antibiotics in veterinary medicine. The spread of ESBLs represents a serious threat to healthcare systems, drastically undermining therapeutic options. The relationship between drug usage and the emergence of resistance has been extensively reported. Nevertheless, the use of antimicrobials in veterinary medicine and the emergence of ESBLs in animals remains a matter of debate. Moreover, there is still controversy about whether antibiotic usage in farm animals poses a potential public health risk. This review will (i) deal with aspects related to the presence of ESBLs in veterinary medicine, (ii) its link with human medicine, and (iii) discuss strategies to be implemented to preserve antimicrobial effectiveness. New insights relative to old questions concerning antimicrobial use in domestic animals are also presented.
\end{abstract}

Key words: antimicrobial therapy; drug resistance; ESBLs; veterinary medicine.

J Infect Dev Ctries 2014; 8(8):954-960. doi:10.3855/jidc.4704

(Received 13 January 2014 - Accepted 04 April 2014)

Copyright (C) 2014 Nóbrega et al. This is an open-access article distributed under the Creative Commons Attribution License, which permits unrestricted use, distribution, and reproduction in any medium, provided the original work is properly cited.

\section{Extended-spectrum beta-lactamases: introduction}

Antimicrobial therapy in veterinary medicine has several applications. Beta-lactams constitute one of the most important groups of antimicrobial agents in veterinary medicine and are the therapy of choice for some well-established practices, including dry cow therapy in dairy cows and weaning therapy in pigs.

Extended-spectrum beta-lactamases (ESBLs) are the most clinically and economically important enzymes that are able to hydrolyze and inactivate betalactam antibiotics in veterinary medicine. On genetic grounds, the presence of ESBLs is associated with resistance to other classes of non-beta-lactam antibiotics, including fluorquinolones, aminoglycosides, and trimethoprim-sulfamethoxazole. In this context, infections caused by these bacteria have limited therapeutic options.

Due to their increasing prevalence, ESBLs quickly became a great burden on human medicine [1,2]. Within the last decade, attention was drawn to animal sources, as there was a rapid increase of infections due to ESBL-producing bacteria. Nowadays, animals live in much closer contact with human populations, and several antimicrobial agents are shared between humans and animals. Moreover, several Gram- negative bacteria that clinically and economically impact veterinary medicine may cause infections in humans.

The increasing prevalence of ESBL-producing bacteria, the growing concern about bacterial resistance, and the lack of biosecurity in the livestock industry of underdeveloped countries were responsible for a substantial rise in the reporting of ESBLs in veterinary medicine. The number of publications referring to ESBL-producing bacteria in veterinary medicine has exponentially increased. ESBLproducing bacteria have already been isolated from bovine mastitis [3], meat products [4], broiler chickens' feces and livers [5], horses [6], swine [7], dairy calves, cows, and dairy farm environment $[8,9]$. As for companion animals, ESBL-producing bacteria have been found in urinary tracts of dogs and cats [10], wound sites, and preputial discharge of companion animals [11], cases of cholangio-hepatitis in dogs [12], and in dog feces [13]. In wild animals, ESBLs have been detected in fecal samples from birds of prey [14], urban brown rats [15], and in seagulls [16].

In particular, numerous studies have underlined that the impact of animal ESBL enzymes on human medicine remains to be determined. Molecular 
epidemiology methods are used to classify the worldwide distribution of ESBL-producing isolates and to describe their underlying resistance mechanisms. General advances in molecular biology methods, with the recent advent of the analysis of clonality using multilocus sequence typing (MLST) in particular, have offered new insights into old issues. This review intends to summarize aspects related to the presence of ESBLs in veterinary medicine and to describe how they affect human health. The impact of antimicrobial use in veterinary medicine and the implementation of strategies to control the use of antimicrobials and preserve their effectiveness are also discussed.

\section{ESBL-positive isolates: a threat to animal and human health}

ESBL-producing bacteria have been isolated from healthy animals [17-19], and can be responsible for self-limiting episodes of gastroenteritis. In this context, is it possible to determine how ESBLs impacts human and veterinary medicine?

Exposure to MDR (multidrug-resistant) bacteria enhances the risk of colonization by these pathogens is enhanced. For instance, travelling to specific countries can be a risk factor for the acquisition of ESBLproducing Enterobacteriaceae among the fecal flora. Several infections, such as sepsis and urinary tract infections caused by ESBL-producing bacteria, are assumed to be caused by the patient's own fecal flora. Overall, this information should be taken into serious consideration, because colonization by MDR bacteria represents a first step towards untreatable infections [20].

Serious human and animal infections caused by bacteria are usually treated with extended-spectrum cephalosporins and other beta-lactams. Therefore, the spread of ESBLs represents a serious threat to healthcare systems. For instance, the risk of a fatal outcome is twofold higher among patients with sepsis caused by ESBL-producing bacteria than among patients infected by susceptible Enterobacteriaceae [21]. Particularly, children and the elderly are susceptible to infections caused by Enterobacteriaceae. For severe, life-threatening infections, antimicrobial therapy can be life saving [22].

The spread of ESBLs undermines therapeutic options. Life-threatening pathogens are now resistant to beta-lactams. To overcome infections caused by ESBL-producing bacteria, it is crucial to turn to more potent drugs. Nevertheless, the discovery of new and more effective drugs has experienced a significant slowing down in the last two decades. In this scenario, it is vital to preserve the effectiveness of the currently available antibiotics.

Hence, it is unquestionable that ESBL-producing bacteria are a threat to human and animal health. Exposure to MDR pathogens may culminate in colonization and possible infection that is not responsive to treatment, in humans and animals alike.

\section{Antimicrobial therapy and emergence of ESBLs in veterinary medicine}

Since the advent of antibiotics in veterinary medicine, the use of beta-lactams has exponentially increased. The massive and indiscriminate use of these antibiotics and their link with a worldwide increase of infections due to ESBL-producing bacteria has drawn the attention of the scientific community. Despite extensive reports on the association between drug usage and resistance [23], the use of antimicrobials in veterinary medicine and the emergence of ESBLs in animals remains a matter of intense debate.

A significant body of the scientific community supports the link between MDR organisms and antimicrobial use in veterinary medicine [24]. Nevertheless, distinct points of view have also been reported. For instance, ESBL-producing bacteria are isolated from broiler farms that do not apply cephalosporin treatments $[5,25]$. In addition, ceftiofur therapy does not seem to increase the amount of resistant bacteria in the intestinal tract of dairy cows [26]. In this scenario, the administration of systemic drugs can, but not necessarily will, collaborate with the emergence and maintenance of antimicrobial resistance genes.

In contrast, cephalosporin therapies seem to increase the occurrence of ESBL-producing bacteria $[27,28]$. In agreement with other researchers, Damborg et al. found that hospitalization and broad-spectrum antimicrobial prophylaxis culminate in fecal shedding of ESBL-producing bacteria in horses [29]. Moreover, antimicrobial resistance may be lower in bacterial isolates from subclinical mastitis cases exactly because these cases are less frequently treated in relation to clinical mastitis [30], although this hypothesis needs to be validated [31].

It is recognized that antimicrobial therapies are linked with the selection of ESBL-producing bacteria. Smith et al. demonstrated that antimicrobial therapies may hasten the emergence of antimicrobial resistance that would, otherwise, be delayed [32]. Theoretically, even if application of antimicrobials had never 
occurred, resistance genes would have accumulated random DNA mutations that would have led to loss of function. In addition, organisms possessing resistance plasmids could have a disadvantage under natural conditions. For instance, several protocols of plasmid curing rely on temperature variation processes. Under stress, bacteria may "cure" the unnecessary resistance plasmid. Notably, the Clinical Laboratory and Standard Institute (CLSI) has recommended that quality control cultures kept under refrigeration temperature should be prepared on a weekly's basis. Indeed, unexplained results have suggested that the inherent susceptibility of the organism might change along time.

Overall, studies support a strong link between drug usage and the emergence of resistance. This connection is more evident in two distinct scenarios: (1) unsuccessful, indiscriminate, and poorly conducted therapies, and (2) off-label use of antibiotics. The latter scenario has been a consequence of the implementation of antibiotics for non-authorized indications [24]. Indiscriminate and poorly conducted therapies are certainly the main reason for the emergence and amplification of drug resistance cases in veterinary medicine [3]. In contrast, in dairy herds, there is very little evidence supporting an increase in antimicrobial resistance due to well-conducted mastitis treatments [33]. Under these circumstances, antimicrobial therapy in veterinary medicine has a minor impact on the emergence of ESBLs.

Antimicrobial therapy can be a risk factor for the emergence of ESBLs for two reasons. First, in undeveloped industries, the absence of protocols for drug administration and storage, failure to establish on-farm treatment records and to verify the compliance of treatment protocols, poor biosecurity, and off-label use of antibiotics are clearly linked to the increased prevalence of ESBL-producing isolates. These overall practices should be discouraged. For instance, the management system accounts for the prevalence of ESBL-producing E. coli in cattle [34]. Moreover, intensive poultry breeding and high concentrations of animals in the same premise favors the transmission of resistant bacteria among animals [35]. In addition, systemic treatments result in elimination of antimicrobial residues through feces, urine, and milk [36]. This scenario supports the selection and transfer of ESBL genes outside the animal level.

The second reason is that different efforts at national levels interfere directly with drug resistance. Guidelines for alternative therapies, monitoring programs, and development of preventive medicine may limit the spread of ESBLs in veterinary medicine. Together, these strategies could certainly reduce the impact of several MDR microorganisms on animal health.

\section{Veterinary antimicrobial therapies and ESBL emergence in human medicine}

The overall quantity of antimicrobials used in the modern livestock industry and their link with human medicine have drawn considerable global attention. Nevertheless, there is still controversy about whether antibiotic usage in farm animals will become a potential public health risk [37].

Points of view that differ from the common belief that antimicrobial therapies in animals may influence human health have also been reported. Phillips et al. reviewed several aspects of antimicrobial therapies in veterinary medicine; they concluded that most of the resistance problems detected in humans originated from human medicine [37]. Animal bacteria do not persist in human intestinal microflora mainly due to lack of host specificity [38]. In this context, ESBLproducing $E$. coli isolated from animals can be different from clinical isolates [39]. Moreover, mathematical models of antimicrobial usage in the farm industry and the emergence of drug resistance in humans strongly suggests that infection control and prudent medical antimicrobial usage rather than elimination of the use of antimicrobials in animals will more likely reduce the prevalence of antimicrobial resistance in hospitals. Medical antimicrobial therapies are largely responsible for human-to-human transmission. Hence, eliminating the use of antimicrobial in livestock animals would have minor effects on the prevalence of antimicrobial resistance in clinical isolates [32].

In contrast, there is strong evidence suggesting that the use of antimicrobials in livestock animals has potential effects on humans [40]. Interspecies transfer between animals and humans has been well documented [41]. Similar gene cassettes are commonly found in animals and in clinical isolates $[17,42]$. Moreover, ESBL-producing E. coli isolated from brown rats and humans share genetic similarities [15]. Notably, an ESBL-positive virulent E. coli isolated from a rat in Berlin was affiliated to ST95, which represents one of the key extraintestinal pathogenic E. coli in humans [43]. With regard to the bacteria specificity, colonization does not seem to be essential for the transfer of resistance traits. Horizontal transfer may take place as resistant bacteria are 
passing through the intestinal tract. Hence, enterococci from animals may enter the hospital environment and eventually transfer resistance genes to well-established isolates [44].

Overall, antimicrobial usage in the farm industry supports the emergence of antimicrobial resistance in clinical isolates through two distinct processes. First, it may increase the occurrence of antimicrobial resistance in zoonotic pathogens. Antimicrobial usage in veterinary medicine may hasten the appearance of MDR pathogens, decreasing the efficacy of antimicrobials in human infections [32]. Second, it may ease the spread of MDR bacteria that exchange genetic material with human commensal bacteria. ESBL genes may undergo horizontal transfer. Highly mobile genetic elements, such as integrons and transposons, may promote lateral transfer among different bacterial species. These isolates are able to transfer resistance traits to others $[45,46]$ and cause opportunistic infections. For instance, treatments and the use of growth promoters in farms might select resistant Salmonella spp. isolates that could, under appropriate circumstances, reach food products $[47,48]$. Although bacteria like Salmonella spp. can be killed during the cooking process, in raw or undercooked chicken meat, the bacteria could survive and enter the human food chain, or exchange genetic material with human pathogenic bacteria. As discussed previously in this review, colonization with ESBLproducing bacteria represents the first step towards untreatable infections. In this context, antimicrobial treatments in animals and contaminated meat products pose a serious threat to human health [35].

Therefore, the dissemination of common resistance traits in both animals and humans provides evidence that animals may act as reservoirs of ESBLs. Furthermore, if humans and animals share similar resistance traits, any unsuccessful antimicrobial therapy in one represents a risk to the other, due to the clear relationship between drug usage and the emergence of drug resistance. Hence, control measures should be encouraged for veterinary and human medicine alike.

\section{How do we prevent the increase of ESBLs from animal origin in human medicine?}

Several sources of ESBLs in veterinary medicine have been reported. Samples from broiler chickens collected at slaughterhouses [49], pets in community and nursing homes [17,46], soil and fecal samples [50,51], and even flies [52] were found to harbor ESBL-positive isolates. As discussed earlier, these isolates may act as ESBL reservoirs in the community. Strategies to assure the preservation of human health should decrease the opportunities for selection of drug-resistant organisms in animals [24]. A multifaceted approach to limit contamination and the spread of ESBLs of animal origin in humans should be encouraged.

It is crucial to identify risk factors associated with the emergence of ESBLs of animal origin. Veterinary medicine has made several advances, which has culminated in the eradication of diseases, gains in productivity, and improvements in public health, in all of which antimicrobial therapy played an important role. However, antimicrobial therapy has long been recognized as the main risk factor for the emergence of drug resistance and is the main reason for the rise of ESBL-producing isolates in animals. A control plan for ESBLs in veterinary medicine must regulate antimicrobial usage in animals. To pursue this strategic point, important antimicrobials for humans should be drastically limited in veterinary medicine. Interestingly, the best time to regulate antimicrobials in veterinary medicine is before the onset of clinically resistant isolates [32]. Zoonotic bacteria would be sensitive to antimicrobials frequently used in human medicine, and only when resistant isolates were considered disseminated should veterinary formulations of the same principles be allowed. Despite being polemic, this strategy would preserve the efficacy of antimicrobials.

Moreover, guidelines regarding the prudent use of antimicrobials should be released. Some well-known strategies can decrease the selection of ESBLs in animals and, consequently, in humans. For instance, the elimination of unnecessary antimicrobial treatments for viral infections, the use of narrowspectrum antibiotics, and the banning of antibiotic use as a growth promoter are strategies that must be implemented [24]. .In addition, alternatives for empirical antimicrobial treatment are currently available or under development and they should be taken into consideration. Probiotics, vaccines, and alternative management systems are known to reduce the number of drug resistance cases in animals [53,54].

Furthermore, the use of distinct antimicrobials classes in human and veterinary medicine is another efficient approach. Veterinarians must be instructed to prescribe appropriate antimicrobials, to ensure their judicious use, and to protect antibiotics that are critically important to humans. National government organizations should work with veterinarians towards a plan of action against ESBLs. These overall 
strategies are effective in preventing the spread of animal ESBLs in the community.

In addition, initiatives ought to be encouraged at a global level, starting with worldwide epidemiologic studies focusing in comparisons between countries that adopt distinct antimicrobial policies. Standardized studies must be performed by several individual research groups and results should be compared. In this context, distinct directives could be evaluated and recommended to specific scenarios. Joint surveillance programs, such as the Canadian Integrated Program for Antimicrobial Resistance Surveillance, must be promoted at a global level. ESBL in veterinary medicine is a global challenge, and individual approaches are not enough to deal with this matter.

Hence, a multifaceted approach is required to both control antimicrobial usage and preserve its effectiveness, with collaboration between human and veterinary medicine [55]. Researchers, official institutions, and professionals should synergistically work on strategies to prevent the emergence and spread of ESBLs in humans and animals. The specific impact of ESBLs in animals cannot be understated.

Overall, the scientific community is clearly worried about the increase of the prevalence of ESBLs producing coliforms in livestock and in companion animals. Several topics discussed in this review can be extrapolated to other antimicrobial agents. We stress the need for global epidemiologic studies in order to prevent an alarming situation. Indeed, infections due to MDR isolates may lead to severe clinical outcomes for humans and animals alike.

\section{Conclusions}

Antimicrobial therapy in veterinary medicine was indubitably responsible for remarkable gains in productivity, leading to eradication of diseases and improvements in animal health. In contrast, the indiscriminate use of antibiotics has led to an increase of ESBLs in animals. More intriguingly, there is evidence suggesting that animals may act as reservoirs of these resistance determinants for humans. In this context, animal ESBL-producing isolates are a threat to both human and animal health. Therefore, it is of primary importance to implement a multifaceted approach to control antimicrobial usage. Global epidemiologic studies should be encouraged in order to preserve antimicrobial effectiveness in both human and veterinary medicine.

\section{References}

1. Lopes AC, Veras DL, Lima AM, Melo Rde C, Ayala J (2010) bla(CTX-M-2) and bla(CTX-M-28) extended-spectrum betalactamase genes and class 1 integrons in clinical isolates of Klebsiella pneumoniae from Brazil. Mem Inst Oswaldo Cruz 105: 163-167.

2. Millan B, Ghiglione B, Diaz T, Gutkind G, Araque M (2011) CTX-M-14 beta-lactamase-producing Citrobacter freundii isolated in Venezuela. Ann Clin Microbiol Antimicrob 10: 22.

3. Locatelli C, Scaccabarozzi L, Pisoni G, Moroni P (2010) CTX-M1 ESBL-producing Klebsiella pneumoniae subsp. pneumoniae isolated from cases of bovine mastitis. J Clin Microbiol 48: 3822-3823.

4. Sunde M, Tharaldsen H, Slettemeas JS, Norstrom M, Carattoli A, Bjorland J (2009) Escherichia coli of animal origin in Norway contains a blaTEM-20-carrying plasmid closely related to blaTEM-20 and blaTEM-52 plasmids from other European countries. J Antimicrob Chemother 63: 215216.

5. Bortolaia V, Guardabassi L, Trevisani M, Bisgaard M, Venturi L, Bojesen AM (2010) High diversity of extendedspectrum beta-lactamases in Escherichia coli isolates from Italian broiler flocks. Antimicrob Agents Chemother 54: 1623-1626.

6. Damborg P, Marskar P, Baptiste KE, Guardabassi L (2012) Faecal shedding of CTX-M-producing Escherichia coli in horses receiving broad-spectrum antimicrobial prophylaxis after hospital admission. Vet Microbiol 154: 298-304.

7. Zou LK, Wang HN, Zeng B, Zhang AY, Li JN, Li XT, Tian GB, Wei K, Zhou YS, Xu CW, Yang ZR (2011) Phenotypic and genotypic characterization of beta-lactam resistance in Klebsiella pneumoniae isolated from swine. Vet Microbiol 149: 139-146.

8. Wittum TE, Mollenkopf DF, Daniels JB, Parkinson AE, Mathews JL, Fry PR, Abley MJ, Gebreyes WA (2010) CTXM-type extended-spectrum beta-lactamases present in Escherichia coli from the feces of cattle in Ohio, United States. Foodborne Pathog Dis 7: 1575-1579.

9. Watson E, Jeckel S, Snow L, Stubbs R, Teale C, Wearing H, Horton R, Toszeghy M, Tearne O, Ellis-Iversen J, Coldham N (2011) Epidemiology of extended spectrum beta-lactamase $E$. coli (CTX-M-15) on a commercial dairy farm. Vet Microbiol 154: 339-346.

10. O'Keefe A, Hutton TA, Schifferli DM, Rankin SC (2010) First detection of CTX-M and SHV extended-spectrum betalactamases in Escherichia coli urinary tract isolates from dogs and cats in the United States. Antimicrob Agents Chemother 54: 3489-3492.

11. Steen SI, Webb PJ (2007) Extended-spectrum beta-lactamaseproducing bacteria isolated from companion animals. Vet Rec 161: 703 .

12. Timofte D, Dandrieux J, Wattret A, Fick J, Williams NJ (2011) Detection of extended-spectrum beta-lactamase positive Escherichia coli in bile isolates from two dogs with bacterial cholangio-hepatitis. J Clin Microbiol 49: 3411-3414.

13. Wedley AL, Maddox TW, Westgarth C, Coyne KP, Pinchbeck GL, Williams NJ, Dawson S (2011) Prevalence of antimicrobial-resistant Escherichia coli in dogs in a crosssectional, community-based study. Vet Rec 168: 354. 
14. Pinto L, Radhouani H, Coelho C, Martins da Costa P, Simoes R, Brandao RM, Torres C, Igrejas G, Poeta P (2010) Genetic detection of extended-spectrum beta-lactamase-containing Escherichia coli isolates from birds of prey from Serra da Estrela Natural Reserve in Portugal. Appl Environ Microbiol 76: 4118-4120.

15. Guenther S, Grobbel M, Beutlich J, Guerra B, Ulrich RG, Wieler LH, Ewers C (2010) Detection of pandemic B2-O25ST131 Escherichia coli harbouring the CTX-M-9 extendedspectrum beta-lactamase type in a feral urban brown rat (Rattus norvegicus). J Antimicrob Chemother 65: 582-584.

16. Poeta $\mathrm{P}$, Radhouani H, Igrejas $\mathrm{G}$, Goncalves A, Carvalho $\mathrm{C}$, Rodrigues J, Vinue L, Somalo S, Torres C (2008) Seagulls of the Berlengas natural reserve of Portugal as carriers of fecal Escherichia coli harboring CTX-M and TEM extendedspectrum beta-lactamases. Appl Environ Microbiol 74: 74397441.

17. Gandolfi-Decristophoris P, Petrini O, Ruggeri-Bernardi N, Schelling E (2013) Extended-spectrum beta-lactamaseproducing Enterobacteriaceae in healthy companion animals living in nursing homes and in the community. Am J Infect Control 41: 831-835.

18. Hammad AM, Ahmed AM, Ishida Y, Shimamoto T (2008) First characterization and emergence of SHV-60 in raw milk of a healthy cow in Japan. J Vet Med Sci 70: 1269-1272.

19. Bortolaia V, Larsen J, Damborg P, Guardabassi L (2011) Potential pathogenicity and host range of extended-spectrum beta-lactamase-producing Escherichia coli isolates from healthy poultry. Appl Environ Microbiol 77: 5830-5833.

20. Ostholm-Balkhed A, Tarnberg M, Nilsson M, Nilsson LE, Hanberger H, Hallgren A (2013) Travel-associated faecal colonization with ESBL-producing Enterobacteriaceae: incidence and risk factors. J Antimicrob Chemother 68: 21442153.

21. Schwaber MJ, Carmeli Y (2007) Mortality and delay in effective therapy associated with extended-spectrum betalactamase production in Enterobacteriaceae bacteraemia: a systematic review and meta-analysis. J Antimicrob Chemother 60: 913-920.

22. Pardos de la Gandara M, Seral C, Castillo Garcia J, Rubio Calvo C, Weill FX (2011) Prevalence and characterization of extended-spectrum beta-lactamases-producing Salmonella enterica isolates in Saragossa, Spain (2001-2008). Microb Drug Resist 17: 207-213.

23. Davies J, Davies D (2010) Origins and evolution of antibiotic resistance. Microbiol Mol Biol Rev 74: 417-433.

24. Seiffert SN, Hilty M, Perreten V, Endimiani A (2013) Extended-spectrum cephalosporin-resistant Gram-negative organisms in livestock: an emerging problem for human health? Drug Resist Updat 16: 22-45.

25. Liebana E, Batchelor M, Hopkins KL, Clifton-Hadley FA, Teale CJ, Foster A, Barker L, Threlfall EJ, Davies RH (2006) Longitudinal farm study of extended-spectrum betalactamase-mediated resistance. J Clin Microbiol 44: 16301634.

26. Singer RS, Patterson SK, Wallace RL (2008) Effects of therapeutic ceftiofur administration to dairy cattle on Escherichia coli dynamics in the intestinal tract. Appl Environ Microbiol 74: 6956-6962.

27. Sun Y, Zeng Z, Chen S, Ma J, He L, Liu Y, Deng Y, Lei T, Zhao J, Liu JH (2010) High prevalence of bla(CTX-M) extended-spectrum beta-lactamase genes in Escherichia coli isolates from pets and emergence of CTX-M-64 in China. Clin Microbiol Infect 16: 1475-1481.

28. Volkova VV, Lanzas C, Lu Z, Grohn YT (2012) Mathematical model of plasmid-mediated resistance to ceftiofur in commensal enteric Escherichia coli of cattle. PLoS One 7: e36738.

29. Damborg P, Marskar P, Baptiste KE, Guardabassi L (2011) Faecal shedding of CTX-M-producing Escherichia coli in horses receiving broad-spectrum antimicrobial prophylaxis after hospital admission. Vet Microbiol 154: 298-304.

30. Bal EB, Bayar S, Bal MA (2010) Antimicrobial susceptibilities of coagulase-negative staphylococci (CNS) and streptococci from bovine subclinical mastitis cases. J Microbiol 48: 267-274.

31. Saini V, McClure JT, Leger D, Keefe GP, Scholl DT, Morck DW, Barkema HW (2012) Antimicrobial resistance profiles of common mastitis pathogens on Canadian dairy farms. J Dairy Sci 95: 4319-4332.

32. Smith DL, Harris AD, Johnson JA, Silbergeld EK, Morris JG, Jr (2002) Animal antibiotic use has an early but important impact on the emergence of antibiotic resistance in human commensal bacteria. Proc Natl Acad Sci USA 99: 6434-6439.

33. Erskine RJ, Walker RD, Bolin CA, Bartlett PC, White DG (2002) Trends in antibacterial susceptibility of mastitis pathogens during a seven-year period. J Dairy Sci 85: 11111118.

34. Dolejska M, Jurcickova Z, Literak I, Pokludova L, Bures J, Hera A, Kohoutova L, Smola J, Cizek A (2011) IncN plasmids carrying bla CTX-M-1 in Escherichia coli isolates on a dairy farm. Vet Microbiol 149: 513-516.

35. Silva N, Costa L, Goncalves A, Sousa M, Radhouani H, Brito F, Igrejas G, Poeta P (2012) Genetic characterisation of extended-spectrum beta-lactamases in Escherichia coli isolated from retail chicken products including CTX-M-9 containing isolates: a food safety risk factor. Br Poult Sci 53: 747-755.

36. Bengtsson B, Unnerstad HE, Ekman T, Artursson K, NilssonOst M, Waller KP (2009) Antimicrobial susceptibility of udder pathogens from cases of acute clinical mastitis in dairy cows. Vet Microbiol 136: 142-149.

37. Phillips I, Casewell M, Cox T, De Groot B, Friis C, Jones R, Nightingale C, Preston R, Waddell J (2004) Does the use of antibiotics in food animals pose a risk to human health? A critical review of published data. J Antimicrob Chemother 53: 28-52.

38. Sorensen TL, Blom M, Monnet DL, Frimodt-Moller N, Poulsen RL, Espersen F (2001) Transient intestinal carriage after ingestion of antibiotic-resistant Enterococcus faecium from chicken and pork. N Engl J Med 345: 1161-1166.

39. Asai T, Masani K, Sato C, Hiki M, Usui M, Baba K, Ozawa M, Harada K, Aoki H, Sawada T (2011) Phylogenetic groups and cephalosporin resistance genes of Escherichia coli from diseased food-producing animals in Japan. Acta Vet Scand 53: 52 .

40. Karp BE, Engberg J (2004) Comment on: Does the use of antibiotics in food animals pose a risk to human health? A critical review of published data. J Antimicrob Chemother 54: 273-274; author reply 276-278.

41. van Loo I, Huijsdens X, Tiemersma E, de Neeling A, van de Sande-Bruinsma N, Beaujean D, Voss A, Kluytmans J (2007) Emergence of methicillin-resistant Staphylococcus aureus of animal origin in humans. Emerg Infect Dis 13: 1834-1839. 
42. Wannaprasat W, Padungtod P, Chuanchuen R (2011) Class 1 integrons and virulence genes in Salmonella enterica isolates from pork and humans. Int J Antimicrob Agents 37: 457-461.

43. Guenther S, Bethe A, Fruth A, Semmler T, Ulrich RG, Wieler LH, Ewers C (2012) Frequent combination of antimicrobial multiresistance and extraintestinal pathogenicity in Escherichia coli isolates from urban rats (Rattus norvegicus) in Berlin, Germany. PLoS One 7: e50331.

44. Heuer OE, Hammerum AM, Collignon P, Wegener HC (2006) Human health hazard from antimicrobial-resistant enterococci in animals and food. Clin Infect Dis 43: 911-916.

45. Sunde M, Norstrom M (2006) The prevalence of, associations between and conjugal transfer of antibiotic resistance genes in Escherichia coli isolated from Norwegian meat and meat products. J Antimicrob Chemother 58: 741-747.

46. Shaheen BW, Nayak R, Foley SL, Kweon O, Deck J, Park M, Rafii F, Boothe DM (2011) Molecular characterization of resistance to extended-spectrum cephalosporins in clinical Escherichia coli isolates from companion animals in the United States. Antimicrob Agents Chemother 55: 5666-5675.

47. Wong MH, Zeng L, Liu JH, Chen S (2013) Characterization of Salmonella food isolates with concurrent resistance to ceftriaxone and ciprofloxacin. Foodborne Pathog Dis 10: 4246.

48. Chiu CH, Su LH, Chu C, Chia JH, Wu TL, Lin TY, Lee YS, Ou JT (2004) Isolation of Salmonella enterica serotype choleraesuis resistant to ceftriaxone and ciprofloxacin. Lancet 363: 1285-1286.

49. Horton RA, Randall LP, Snary EL, Cockrem H, Lotz S, Wearing H, Duncan D, Rabie A, McLaren I, Watson E, La Ragione RM, Coldham NG (2011) Fecal carriage and shedding density of CTX-M extended-spectrum betalactamase-producing Escherichia coli in cattle, chickens, and pigs: implications for environmental contamination and food production. Appl Environ Microbiol 77: 3715-3719.

50. Radhouani H, Pinto L, Coelho C, Goncalves A, Sargo R, Torres C, Igrejas G, Poeta P (2010) Detection of Escherichia coli harbouring extended-spectrum beta-lactamases of the CTX-M classes in faecal samples of common buzzards (Buteo buteo). J Antimicrob Chemother 65: 171-173.

51. Kojima A, Ishii $\mathrm{Y}$, Ishihara $\mathrm{K}$, Esaki $\mathrm{H}$, Asai $\mathrm{T}$, Oda $\mathrm{C}$, Tamura Y, Takahashi T, Yamaguchi K (2005) Extendedspectrum-beta-lactamase-producing Escherichia coli strains isolated from farm animals from 1999 to 2002: report from the Japanese Veterinary Antimicrobial Resistance Monitoring Program. Antimicrob Agents Chemother 49: 3533-3537.

52. Usui M, Iwasa T, Fukuda A, Sato T, Okubo T, Tamura Y (2013) The role of flies in spreading the extended-spectrum beta-lactamase gene from cattle. Microb Drug Resist 19: 415420.

53. Park YK, Fox LK, Hancock DD, McMahan W, Park YH (2012) Prevalence and antibiotic resistance of mastitis pathogens isolated from dairy herds transitioning to organic management. J Vet Sci 13: 103-105.

54. Doyle MP, Erickson MC (2006) Reducing the carriage of foodborne pathogens in livestock and poultry. Poult Sci 85 : 960-973.

55. Paphitou NI (2013) Antimicrobial resistance: action to combat the rising microbial challenges. Int $\mathrm{J}$ Antimicrob Agents 42 Suppl: S25-28.

\section{Corresponding author}

Diego Borin Nóbrega,

Department of Genetics, Evolution, and Bioagents, Institute of

Biology, University of Campinas, (UNICAMP),

Monteiro Lobato Street, 255. CEP 13083-862,

Barão Geraldo District, Campinas, Brazil

Phone: + 55 19) 35216274

Fax: +55 1935216185

Email: diegoborin@yahoo.com.

Conflict of interests: No conflict of interests is declared. 